\title{
Hyperbaric oxygen therapy in the treatment of brain abscess: about a case
}

Cherkaoui Mandour, Miloudi Gazzaz, Brahim El Mostarchid MOROCCO 


\title{
Hyperbaric oxygen therapy in the treatment of brain abscess: about a case
}

\author{
Cherkaoui Mandour, Miloudi Gazzaz, Brahim El Mostarchid \\ Department of neurosurgery, Military Hospital Mohammed V - Rabat, MOROCCO
}

\begin{abstract}
The management of brain abscess remains a challenging topic usually involving a multimodal concept. The efficiency of hyperbaric oxygen therapy is currently being used in many areas, and has been proven in infections with deep and superficial location. We report our experience with hyperbaric oxygen therapy combined with antibiotics in the treatment of this disease in a children case. The evolution was very favourable; we believe that the hyperbaric oxygen therapy is a reliable adjuvant therapy for brain abscess.
\end{abstract}

Key words: Brain abscess, Hyperbaric oxygen therapy, Stereotactic

\section{Introduction}

Brain abscess continues to constitute one of the most important neurosurgical diseases and the management still presents a challenging problem $(3,5,6,11)$. In recent years, there is increasing tendency to use a safe and effective therapeutic means. We report a case of a child who was treated for a brain abscess with stereotactic aspiration combined with antibiotic and hyperbaric oxygen (HBO) therapy.

\section{Case report}

A 17-year-old male, was admitted to the hospital with signs of intracranial hypertension and fever. Neurological examination revealed no disturbances of consciousness no motor or sensory deficit.
Brain magnetic resonance imaging revealed a right frontal abscess (Figures 1-2). Abscess was treated by stereotactic aspiration combined with $\mathrm{HBO}$ and systemic antibiotic therapy. The patient received $\mathrm{HBO}(100 \% \mathrm{O} 2$ at 2.5 ATA for $90 \mathrm{~min}$ ) for 30 days and intravenous antibiotics for 4-week.

Clinical and radiological evolution was very favorable. After one week Computed tomography (CT) of brain showed a total regression of the abscesses (Figure 3).

\section{Discussion}

Bacterial brain abscess continues to constitute one of the most important neurosurgical diseases. Its management can be done by several methods: antibiotics alone (12, 13) drainage, aspiration, and excision $(2,13)$. 
The choice of procedure may be influenced by the age and neurological condition of the patient, location, stage of the abscess and the type of abscess. Some surgical management has been revolutionized by the development of image-guided stereotaxy that has proven to be a relatively simple and safe method.

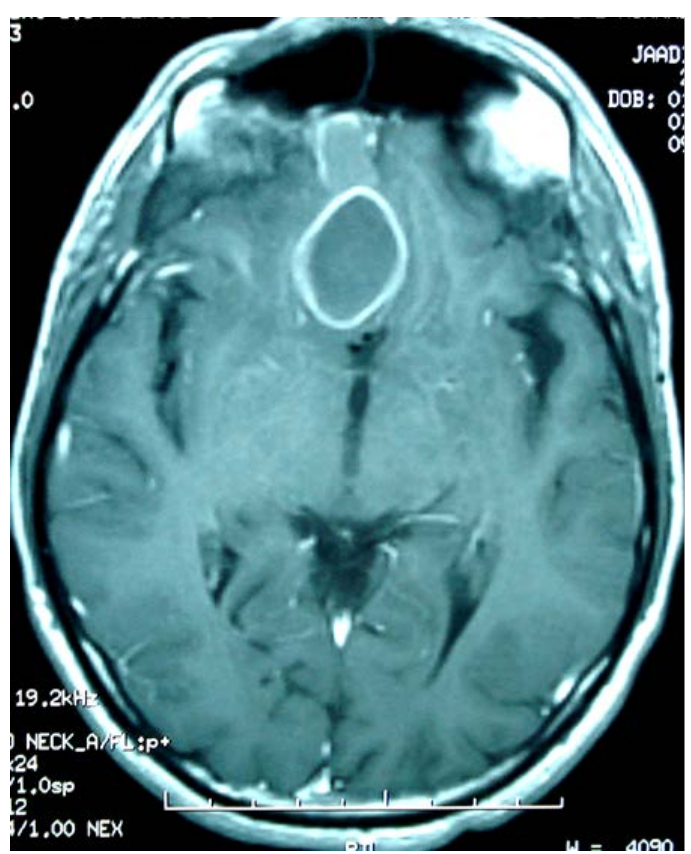

Figure 1 - Gadolinium-enhanced axial T1-weighted MRI scans showing a right frontal abscess

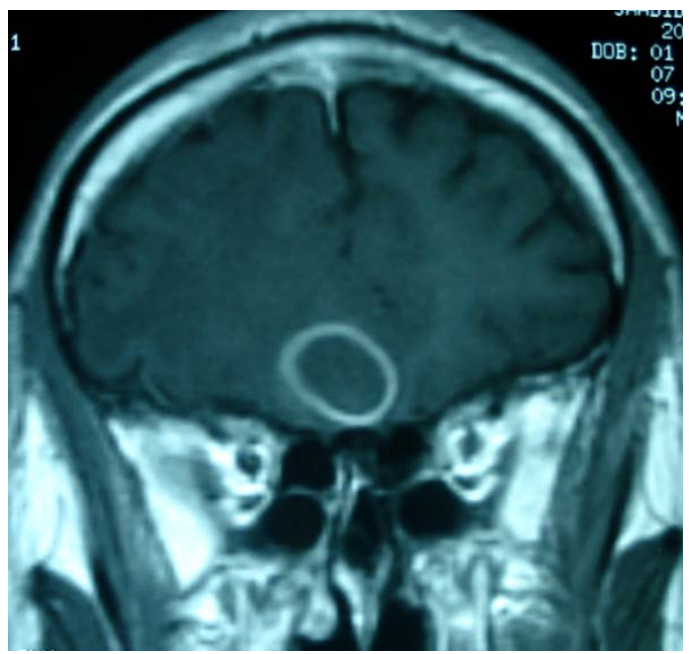

Figure 2 - Gadolinium-enhanced coronal T1weighted MRI scans showing a right frontal abscess

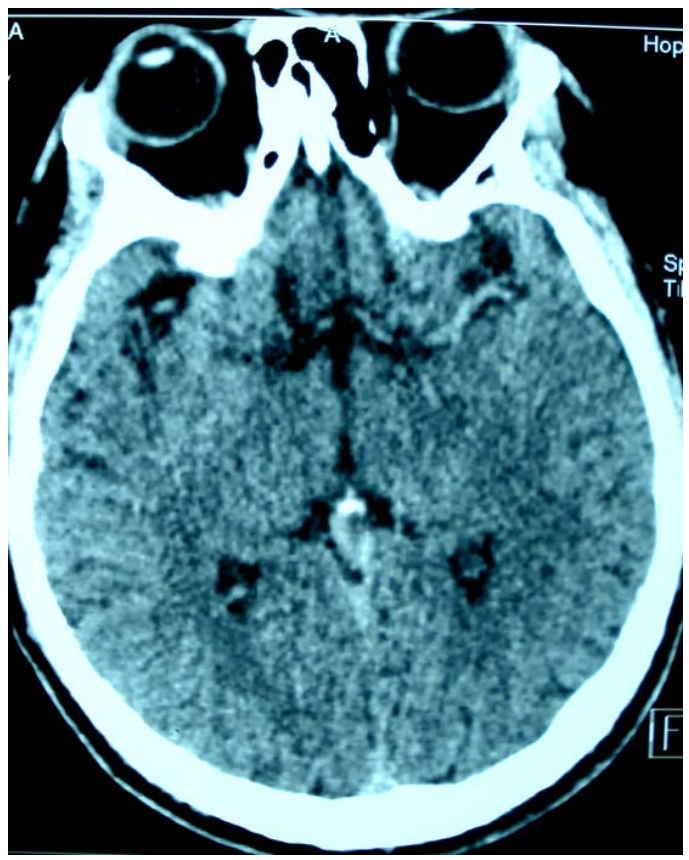

Figure 3 - Computed tomography (CT) of brain after one week, revealing a complete resolution of the abscess 
Antibiotics continue to be an integral part of the treatment of intracranial abscesses (1, 11) and the use of HBO therapy as like as an adjunctive treatment has been approved by the Undersea and Hyperbaric Medical Society since 1996 (4). Hyperbaric oxygen exerts influence on tissues via a lot of mechanisms: One of the most important effects is stimulation of the bactericidal action of white blood cells (11). It has been reported that the leukocyte bacteria-killing capacity is substantially impaired in hypoxic surroundings (11).

$\mathrm{HBO}$ therapy increases the oxygen tension in infected tissues, resulting in improvements in phagocytic killing of bacteria direct bactericidal effects on some microorganisms (11). Additionally, improved tissue oxygen tensions in ischemic tissues during $\mathrm{HBO}$ therapy inhibits the growth of aerobic and facultative anaerobic bacteria by inducing a variety of metabolic effects involved with the synthesis of proteins, nucleic acids and essential cofactors of metabolic reactions $(9,10)$.

A combination of $\mathrm{HBO}$ and stereotactic aspiration in the management of brain abscesses is very important because stereotactic aspiration minimize iatrogenic brain damage caused by brain retraction and dissection, it also minimizes operation time and hospital stay $(3,5,11)$. On the other hand, hyperbaric oxygen (HBO) has remarkable results in neurosurgical infections $(7,8)$.

\section{Conclusion}

It is believed that hyperbaric oxygen is an important adjunctive traitement in the management of brain abscess, because it can reduce the length of time on antibiotics.

\section{Correspondence}

Cherkaoui Mandour

E-mail:mandour1978@hotmail.com

Telephone: 2120653421225

Miloudi Gazzaz

E-mail: gmilou@hotmail.com

Telephone: 2120648348005

Brahim El Mostarchid

E-mail:elmostarchid@hotmail.com

Telephone: 2120648348945

\section{References}

1.Barlas O, Sencer A, Erkan K, Eraksoy H, Sencer S, Bayındır C: Stereotactic surgery in the management of brain abscess. Surg Neurol,1999,52:404-410.

2.Beller AJ, Sahar A, Praiss I: Brain abscess: Review of 89 cases over a period of 30 years. J Neurol Neurosurg Psychiatry,1973,36: 757-768.

3.Haines SS, Mampalam T, Rosenblum ML, Nagrib MG: Cranial and intracranial bacterial infections, in Youmans JR (ed): Neurological Surgery. W.B.

4.Hampson NB:Hyperbaric Oxygen Therapy:1999 Committe Report. Kensington, Undersea and Hyperbaric Medical Society, 1999, pp 1-82.

5.Kole KM, Rosenblum ML: Management of multiple brain abscesses, in Batjer HH, Loftus CM (eds): Textbook of Neurological Surgery. Principles and Practice. Philadelphia, Lippincott Williams and Wilkins, 2003, pp 3151-3157.

6.Kurschel S, Mohia A, Weigl V, Eder HG. Hyperbaric oxygen therapy for the treatment of brain abscess in children. Childs Nerv Syst. 2006 Jan,22(1):38-42.

7.M. Kutlay, A. Colak, H. Simsek, S. Yildiz, K. Topuz, S. Kaya, A. Cetinkal, M. Demircan. Antibiotic and hyperbaric oxygen therapy in the management of postoperative discitis. Undersea and Hyperbaric Medical Society. 2008, Vol. 35, No. 6

8.A. Larsson • J. Uusija"rvi • F. Lind • B. Gustavsson • H. Saraste. Hyperbaric oxygen in the treatment of 
postoperative infections in paediatric patients with neuromuscular spine deformity. Eur Spine J (2011) 20:2217-2222

9.Lampl LA, Frey G: Hyperbaric oxygen in intracranial abscess, in Kindwall EP (ed): Hyperbaric Medicine Practise. Arizona, Best Publishing Co., 1995, pp 661-670. 10.Mehmet Resid Onen, Sait Naderi. Role of Hyperbaric Oxygen Therapy in Spinal

Pathologies. World Spinal Column Journal, Volume 6 / No: 1 / January 2015

11.Murat Kutlay, Ahmet Colak, Senol Yildiz, Nusret Demircan, Osman Niyazi Akin Stereotactic aspiration and antibiotic treatment combined with hyperbaric oxygen therapy in the management of bacterial brain abcesses.Neurosurgery 2005, 57:1140-1146.

12.Rosenblum ML, Hoff JT, Norman D, Weinstein PR, Pitts L: Decreased mortality from brain abscesses since advent of computerized tomography.

J Neurosurg,1978,49:658-668.

13. Rosenblum ML, Mampalam TJ, Pons VG: Controversies in the management of brain abscesses. Clin Neurosurg,1986,33:603-632. 